\title{
Análise Sobre as Propostas de Reforma Tributária: as Lições da Crise da COVID-19
}

\author{
Analysis on Tax Reform Proposals: Lessons from the Covid-19 Crisis
}

\author{
Mickael Ferreira Alves
}

Faculdade Pitágoras de Belo Jardim, Curso de Direito. PE, Brasil.

Email: mickael.alves@kroton.com.br

\begin{abstract}
Resumo
É a primeira vez que o Brasil vivencia uma crise de saúde nessa escala e com consequências tão graves na economia. A queda do PIB brasileiro, bem como em diversos países do Globo, em 2020, será inevitável. Os projetos de reforma tributária devem ser permeados por debates mais práticos para a criação de gatilhos para impulsionar a economia nacional. Em função do sistema tributário brasileiro atual totalmente caótico e com essa terrível crise da COVID-19 que pegou todos de surpresa, o presente artigo tem como objetivo verificar os principais aspectos dos projetos de Reforma Tributária com o fito de retomada na economia com o fortalecimento de novos negócios em um mundo pós-pandemia. O estudo se caracterizou por ser uma pesquisa bibliográfica, de caráter exploratório, realizada por meio de livros, leis, códigos e artigos científicos. Diante da possibilidade de uma Reforma Tributária brasileira, resta saber como poderá ser visto um sistema tributário nacional em um momento de pós-pandemia.
\end{abstract}

Palavras-chave: Crise. Economia. Pandemia. Reforma Tributária.

\begin{abstract}
It is the first time that Brazil has experienced a health crisis on this scale and with such serious consequences for the economy. The fall in Brazilian GDP, as well as in several countries around the globe, in 2020 will be inevitable. Tax reform projects must be permeated by more practical debates to create triggers to boost the national economy. Due to the current totally chaotic Brazilian tax system and with this terrible covid-19 crisis that took everyone by surprise, this article aims to verify the main aspects of tax reform projects with the aim of resuming the economy with the strengthening of new businesses in a post-pandemic world. The study was characterized by being an exploratory bibliographic research, carried out through books, laws, codes and scientific articles. Given the possibility of a Brazilian tax reform, it remains to be known how a national tax system can be seen in a post-pandemic moment.
\end{abstract}

Keywords: Crisis. Economy. Pandemic. Tax Reform.

\section{Introdução}

A necessidade de uma Reforma Tributária é consenso nacional, principalmente, agora em função da COVID-19 que esfacelou a economia brasileira. No entanto, delimitar exatamente quais os pontos principais a serem incluídos nas propostas ainda é algo que deixa dúvidas. Uma coisa é certa: mais cedo ou mais tarde a Reforma Tributária terá de ser feita.

Muitas discussões como a de que o país se encaminha para ter um imposto simplificado sobre bens e serviços, que os incentivos fiscais precisam ser reavaliados, que a Zona Franca de Manaus perderá espaço e outros são assuntos polêmicos e que possuem um caráter estratégico dentro dos projetos de Reforma Tributária.

Os brasileiros costumam se referir ao Sistema Tributário Nacional de forma pouco lisonjeira. Chamam-no de "carnaval tributário", "Frankenstein". Esse pouco apreço tem sua razão de ser. As empresas do país comprometem uma parte significativa do seu faturamento anual apenas para administrar os 63 tributos e as mais de 90 obrigações acessórias existentes.

A partir dessa leitura, segundo o último estudo realizado pela Secretaria da Receita Federal do Brasil-SRFB (2018) a carga tributária bruta (CTB) atingiu 33,26\% contra 32,33\% em 2017 , indicando variação positiva de 0,93 pontos percentuais (Tabela 01). Essa variação resultou da combinação dos acréscimos em termos reais de 1,3\% do Produto Interno Bruto e de $4,2 \%$ da arrecadação tributária nos três níveis de Governo.

A complexidade da legislação gera medo. Incomoda, também, o volume da carga tributária, bastante elevado no que tange ao consumo de bens e serviços. O sistema é pouco transparente, cumulativo ("imposto sobre imposto") e regressivo, onerando desproporcionalmente o contribuinte de baixa renda (FALLEIROS, 2019).

Nos corredores do Congresso Nacional, duas propostas de reforma tributária ganharam força nos últimos meses: a da PEC no 45/2019, que tramita na Câmara dos Deputados; e a da PEC no 110/2019, no Senado Federal. A espinha dorsal de ambas é a criação de um imposto sobre o consumo de bens e serviços (IBS), capaz de reunir diversos tributos esparsos em uma só cobrança. Em essência, o IBS é um IVA (Imposto sobre Valor Agregado), modelo adotado pelos países da União Europeia, por exemplo (FALLEIROS, 2019). 
O cenário fiscal e econômico no Brasil é preocupante, em todos os níveis. Inclusive, vários Estados e municípios estão desequilibrados financeiramente. Uma Reforma Tributária poderia evitar esse abismo, claro que não de forma imediata, porque precisaria de um período de transição entre o atual sistema tributário e o novo, principalmente, com muitas questões consideradas agora novas em virtude da pandemia. Este é um problema político de grande magnitude, então, para que a Reforma Tributária ocorra é fundamental que haja consenso, pelo menos, a maioria tem que ter assentido que isso é necessário. Todos têm que entender que perdas e ganhos tributários serão inevitáveis, até porque o Brasil é um país de tamanho continental, com cinco regiões geográficas com peculiaridades locais, tais como, economia, clima, vegetação, educação e outros. Nesse diapasão é importante mencionar que os tributos existem para que o Governo possa garantir a prestação de serviços perante a sociedade, como segurança pública, saúde, educação, saneamento básico.

Dessa forma, no presente trabalho emergiu a seguinte questão de pesquisa: como poderá ser visto um sistema tributário nacional em um momento de pós-pandemia?

Passa-se adiante a um esboço sobre as PECs de Reforma Tributária em tramitação.

\section{Desenvolvimento}

\subsection{Metodologia}

Caracterizando o estudo, em relação aos métodos científicos quanto à abordagem, essa ocorreu pelo método dedutivo, tendo em vista a generalização, ou seja, partiu de algo particular para uma questão mais ampla, mais geral.

Com relação aos métodos científicos quanto aos procedimentos o presente trabalho ocorreu de forma comparativa, ocupou-se da explicação dos fenômenos permitindo analisar o dado concreto, deduzindo desse os elementos constantes, abstratos e gerais.

E com relação $\grave{a}$ pesquisa em si, quanto $\grave{a}$ natureza se percebeu como sendo aplicada, porque objetivou gerar conhecimentos para aplicação prática dirigidos à solução de problemas específicos relacionados às questões tributárias.

Já do ponto de vista de seus objetivos, a pesquisa se realizou como exploratória e explicativa em função do uso de material bibliográfico através de material já publicado em fontes oficiais como a Receita Federal, Senado Federal e Câmara dos Deputados Federais, o que explica também em dizer ser a pesquisa quanto aos procedimentos como sendo bibliográfica.

E, por último, quanto à forma de abordagem, a pesquisa ocorreu como quantitativa, por tentar traduzir em números opiniões e informações com relação às questões dos projetos de Reforma Tributária.

\subsection{Reforma Tributária: PEC 110/2019 e PEC 45/2019}

Antes de adentrar nos projetos de Emenda Constitucional referentes à Reforma Tributária é importante trazer números sobre a composição da atual carga tributária por ente federativo, conforme dados extraídos da Receita Federal (2018) em seu último levantamento oficial.

Quadro 1 - Carga Tributária por Ente Federativo

\begin{tabular}{|c|c|c|c|c|c|c|c|c|c|c|}
\hline \multirow{3}{*}{$\begin{array}{l}\text { Entidade } \\
\text { Federativa }\end{array}$} & \multicolumn{3}{|c|}{2017} & \multicolumn{3}{|c|}{2018} & \multicolumn{4}{|c|}{ Variação } \\
\hline & \multirow{2}{*}{$\begin{array}{l}\text { Arrecadação } \\
\text { [R\$ milhões] }\end{array}$} & \multirow{2}{*}{$\begin{array}{l}\% \text { do } \\
\text { PIB }\end{array}$} & \multirow{2}{*}{$\begin{array}{c}\% \text { da } \\
\text { Arrecad. }\end{array}$} & \multirow{2}{*}{$\begin{array}{l}\text { Arrecadação } \\
\text { [R\$ milhões }]\end{array}$} & \multirow{2}{*}{$\begin{array}{l}\% \text { do } \\
\text { PIB }\end{array}$} & \multirow{2}{*}{$\begin{array}{c}\% \mathrm{da} \\
\text { Arrecad. }\end{array}$} & \multicolumn{2}{|c|}{$\begin{array}{l}\text { Arrecadação [R } \$ \\
\text { milhões }]\end{array}$} & \multirow{2}{*}{$\begin{array}{c}\text { p.p } \\
\text { do } \\
\text { PIB }\end{array}$} & \multirow{2}{*}{$\begin{array}{l}\text { p.p da } \\
\text { Arrecad. }\end{array}$} \\
\hline & & & & & & & Nominal & Real & & \\
\hline União & $1.448 .349,32$ & $22,00 \%$ & $68,04 \%$ & $1.547 .402,45$ & $22,46 \%$ & $67,53 \%$ & $99.053,14$ & $51.468,49$ & 0,46 & $-0,51$ \\
\hline Estados & $547.073,54$ & $8,31 \%$ & $25,70 \%$ & $593.382,08$ & $8,61 \%$ & $25,90 \%$ & $46.308,54$ & $28.334,77$ & 0,3 & 0,20 \\
\hline Municípios & $133.189,98$ & $2,02 \%$ & $6,26 \%$ & $150.622,55$ & $2,19 \%$ & $6,57 \%$ & $17.432,57$ & $13.056,69$ & 0,16 & 0,32 \\
\hline Total & $2.128 .612,84$ & $32,33 \%$ & $100 \%$ & $2.291 .407,08$ & $33,26 \%$ & $100 \%$ & $162.794,24$ & $92.859,95$ & 0,93 & 0,00 \\
\hline
\end{tabular}

Fonte: Receita Federal.

Atualmente, são tributados no Brasil bens e serviços, renda, patrimônio e folha de salários, e as empresas estão obrigadas ou por escolha a tributar pelo Simples Nacional, Lucro Real ou Presumido, segue o Quadro 2 que mostra o atual cenário tributário no país:

Quadro 2 - Tributação no Brasil

\begin{tabular}{|c|c|}
\hline & Tributos \\
\hline Bens e serviços & PIS, Cofins, IPI, II, IE, IOF, Cide, ICMS e ISS \\
\hline Renda & IRPF, IRPJ, CSLL e IRRF \\
\hline Patrimônio & ITR, IPVA, ITCMD, IPTU e ITBI \\
\hline Folha de & $\begin{array}{c}\text { Contribuição previdenciária, Salário Educação, } \\
\text { Salários }\end{array}$ \\
\hline
\end{tabular}

Fonte: Dados da pesquisa.
A PEC n ${ }^{\circ} 45$ é de autoria do Deputado Federal Baleia Rossi e teve o conteúdo idealizado pelo economista Bernard Appy, diretor do CCiF (Centro de Cidadania Fiscal). O texto guarda semelhanças com a proposta trazida pelos Secretários de Fazenda dos Estados e do DF e conta com o apoio declarado do presidente da Câmara dos Deputados, Rodrigo Maia.

Já a PEC nº 110 é uma iniciativa de líderes partidários e teve como primeiro signatário o senador Davi Alcolumbre, presidente da Casa. O mentor intelectual deste texto é o economista e ex-Deputado Federal Luiz Carlos Hauly.

A partir dessa leitura em ambas as proposições das PEC 45 e 110, a alteração do Sistema Tributário Nacional tem como principal objetivo a simplificação e a racionalização 
da tributação sobre a produção e a comercialização de bens e a prestação de serviços, base tributável atualmente compartilhada pela União, Estados, Distrito Federal e Municípios (CORREIA NETO et al., 2019).

Nesse sentido, ambas propõem a extinção de uma série de tributos, consolidando as bases tributáveis em dois novos impostos:

(i) um imposto sobre bens e serviços (IBS), nos moldes dos impostos sobre valor agregado cobrados na maioria dos países desenvolvidos; e

(ii) um imposto específico sobre alguns bens e serviços denominado de Imposto Seletivo.

Pela competência tributária do IBS, na PEC 110, existiria um tributo estadual, instituído por intermédio do Congresso
Nacional, com poder de iniciativa reservado, basicamente, a representantes dos Estados e Municípios (exceto por uma comissão mista de Senadores e Deputados Federais criada, especificamente, para esse fim ou por bancada estadual).

Já na PEC 45 existiria um Tributo Federal instituído por meio de lei complementar federal, exceto em relação à fixação da parcela das alíquotas destinadas à União, aos Estados, ao Distrito Federal e aos Municípios, a ser definida por lei ordinária de cada ente federativo.

Dessa feita, na PEC 110 são substituídos nove tributos, o IPI, IOF, PIS, Pasep, Cofins, CIDE-Combustíveis, SalárioEducação, ICMS, ISS e na PEC 45 são substituídos cinco tributos, o IPI, PIS, Cofins, ICMS, ISS.

Quadro 3 - Diferenças entre as principais propostas de Reforma Tributária

\begin{tabular}{|c|c|c|}
\hline & PEC n. 110/2019 & PEC n. 45/2019 \\
\hline & $\begin{array}{c}\text { Senado Federal } \\
\text { Idealizada por Luiz Carlos Hauly, economista e } \\
\text { ex-deputado federal }\end{array}$ & $\begin{array}{c}\text { Câmara dos Deputados } \\
\text { Idealizada por Bernard Appy, economista e } \\
\text { diretor do CCiF (Centro de Cidadania Fiscal) }\end{array}$ \\
\hline $\begin{array}{l}\text { Tributos a serem substituídos } \\
\text { pelo imposto único (IBS) }\end{array}$ & $\begin{array}{l}\text { IPI, PIS, Cofins, IOF, Salário Educação, ICMS e } \\
\text { ISS }\end{array}$ & IPI, PIS, Cofins, ICMS e ISS \\
\hline Gestão & $\begin{array}{l}\text { \# IBS Federal: Receita Federal do Brasil. } \\
\text { \# IBS Estadual: comitê gestor dos representantes } \\
\text { dos Estados, DF e dos municípios. }\end{array}$ & $\begin{array}{l}\text { Comitê gestor do IBS, com representantes de } \\
\text { todos os entes federados, incluindo a União. }\end{array}$ \\
\hline Alíquotas & $\begin{array}{l}\text { Proposta de IBS, com uma alíquota para a União } \\
\text { e outra para estados e municípios }\end{array}$ & $\begin{array}{l}\text { Cada ente da federação terá autonomia para fixar } \\
\text { a sua alíquota dentro de uma margem. }\end{array}$ \\
\hline Período de transição & $\begin{array}{l}\text { Cinco anos. Período de teste de um ano, com } \\
\text { alíquota de } 1 \% \text {. Após o período de teste, redução } \\
\text { dos tributos atualmente cobrados na proporção } \\
\text { de } 20 \% \text { ao ano e aumento gradual do IVA até o } \\
\text { cumprimento da meta da arrecadação. }\end{array}$ & $\begin{array}{l}\text { Dez anos. Período de teste de dois anos, com } \\
\text { alíquota de } 1 \% \text {. Após o período de teste, redução } \\
\text { dos tributos atualmente cobrados na proporção } \\
\text { de } 10 \% \text { ao ano e aumento gradual do IVA até o } \\
\text { cumprimento da meta de arrecadação. }\end{array}$ \\
\hline Repartição de receitas & $\begin{array}{l}\text { Período de transição de } 15 \text { anos para a repartição } \\
\text { das receitas do IBS entre Estados, DF e } \\
\text { municípios. }\end{array}$ & $\begin{array}{l}\text { Período de transição de } 50 \text { anos para a repartição } \\
\text { das receitas do IBS entre Estados, DF e } \\
\text { municípios. }\end{array}$ \\
\hline
\end{tabular}

Fonte: Dados da pesquisa. (2020)

De fato, todo processo de Reforma Tributária tende a ser demorado e conflituoso, por ser o resultado do confronto de ideias discrepantes sobre o melhor modelo fiscal a ser adotado para todo o país. Diante da importância do assunto, renomados professores, advogados, economistas e especialistas no assunto afirmam que uma tributação que colocasse valores não tão oneroso à distribuição de renda é a chance para o Brasil promover o crescimento e, principalmente, o desenvolvimento econômico.

A carga é regressiva por ser centrada no consumo, quando deveria ser focada na renda para vigorar o princípio da progressividade: ganhou mais, pagou mais. O sistema tributário brasileiro como um todo fere claramente o princípio da capacidade contributiva dos contribuintes em seus diferentes rendimentos.

Outra questão importante, em uma eventual Reforma Tributária seria o período de transição do sistema de cobrança dos tributos, em que na PEC 110 durante um ano é cobrada uma contribuição "teste" de 1\%, com a mesma base de incidência do IBS e, depois, a transição dura cinco anos, sendo os atuais tributos substituídos pelos novos tributos à razão de um quinto ao ano (os entes federativos não podem alterar as alíquotas dos tributos a serem substituídos), enquanto a PEC 45 durante dois anos é cobrada uma contribuição "teste" de $1 \%$, com a mesma base de incidência do IBS e, depois, a transição dura oito anos, sendo os atuais tributos substituídos pelos novos tributos à razão de um oitavo ao ano (os entes federativos podem alterar as alíquotas dos tributos a serem substituídos).

Sobre um chamado Imposto Seletivo, a PEC $110 \mathrm{diz}$ que seria um imposto de índole arrecadatória, cobrado sobre operações com petróleo e seus derivados, combustíveis e lubrificantes de qualquer origem, gás natural, cigarros e outros produtos do fumo, energia elétrica, serviços de telecomunicações a que se refere o art. 21, XI, da Constituição Federal, bebidas alcoólicas e não alcoólicas, e veículos automotores novos, terrestres, aquáticos e aéreos, enquanto na PEC 45 seriam impostos de índole extrafiscal, cobrados sobre determinados bens, serviços ou direitos com o objetivo de desestimular o consumo. Não são listados sobre quais produtos ou serviços o tributo irá incidir. Caberá à lei 
(ordinária) ou medida provisória instituidora definir os bens, serviços ou direitos tributados.

Além do rearranjo da tributação sobre bens e serviços, a PEC 110 contempla outras matérias não previstas na PEC 45, sendo as mais destacadas da seguinte maneira:

a. extinção da Contribuição Social sobre o Lucro Líquido (CSLL), sendo sua base incorporada ao Imposto de Renda da Pessoa Jurídica (IRPJ);

b. transferência do Imposto sobre Transmissão Causa Mortis e Doação (ITCMD), da competência estadual para a federal, com a arrecadação integralmente destinada aos Municípios;

c. ampliação da base de incidência do Imposto sobre Propriedade de Veículo Automotor (IPVA), para incluir aeronaves e embarcações, com a arrecadação integralmente destinada aos Municípios;

d. autorização de criação de adicional do IBS para financiar a previdência social;

e. criação de fundos estadual e municipal para reduzir a disparidade da receita per capita entre os Estados e Municípios, com recursos destinados a investimentos em infraestrutura.

Passa-se as questões envolvendo a pandemia da COVID-19 frente às propostas de Reforma Tributária em tramitação.

\subsection{COVID-19 e a Reforma Tributária}

A pandemia do novo Coronavírus mudou o eixo de discussão da Reforma Tributária. Antes muito dirigida às mudanças na composição de impostos sobre o consumo, agora ganham espaço propostas que tratam da tributação sobre a renda.

A Receita Federal afirmou recentemente, através de um dos seus secretários que o Governo quer promover uma desoneração da folha de pagamento para estimular a recuperação de empregos após a crise, e que a redução de benefícios fiscais ou revisão de alíquotas de outros tributos pode dar suporte à investida. A revisão dos encargos sobre a folha de pagamento das empresas viria para estimular a formalização do emprego.

Dessa forma, do ponto de vista técnico, urgentemente devem ser revistas as alíquotas na tabela progressiva do IR das pessoas físicas, rumo a uma maior progressividade e no conjunto de deduções e abatimentos que hoje são possíveis. Já para a apuração no lucro real, por exemplo, hoje existem muitas adições e exclusões que tornam esse processo bastante complexo.

O CCIF (Centro de Cidadania Fiscal) elaborou uma proposta de desoneração da folha de pagamento, que reduz o custo de contratação em todas as faixas de salário e coloca as contribuições praticamente no mesmo nível dos benefícios gerados. Essa proposta inclui a desoneração parcial do primeiro salário-mínimo da renda de todos os trabalhadores, o fim da contribuição patronal sobre a parcela que excede o teto do salário de contribuição e a eliminação de contribuições não previdenciárias.

A reação do Brasil à COVID-19 pode ser examinada sob várias perspectivas. Sob o ângulo tributário, foi confusa, para se dizer o mínimo. No sistema tributário atual cabe a cada ente federativo editar as normas aplicáveis ao recolhimento dos tributos de sua competência e respectivas obrigações acessórias (emissão de nota fiscal, apresentação de declarações etc.).

As inúmeras normas propostas e publicadas pela Secretaria da Receita Federal, Procuradoria da Fazenda Nacional e pelo Banco Central, por exemplo, em âmbito federal, bem como por cada um dos 26 Estados, Distrito Federal e mais de 5 mil Municípios do país, promovem verdadeiro caos e impedem a estabilização da economia no momento em que isso é mais importante (PEROBA; CORREA, 2020).

Caso já tivesse sido implementada a Reforma Tributária dos tributos sobre o consumo, seria possível instaurar um comitê único para debate das questões relacionadas à crise da COVID-19 e a edição de uma única norma, uma lei complementar, por exemplo, clara e transparente.

Com isso, certamente, esse cenário traria benefícios ao fisco, como uma melhor gestão e fiscalização, bem como aos contribuintes que conseguiriam arrecadar, de forma mais clara, sem correr tanto risco de autuações fiscais, tudo isso para que as autoridades públicas pudessem focar em outras questões que devem ser endereçadas pelo Poder Público (como a saúde, educação, apoio aos trabalhadores e à população carente).

A proposta, que tem fundamento em um amplo e atual estudo econômico, tem como escopo não só a redução da carga tributária, mas principalmente, a melhoria do próprio sistema tributário, com base nos princípios da simplicidade, transparência, neutralidade e equidade, os quais, definitivamente, não informam o atual sistema tributário brasileiro.

Algumas propostas de cunho mundial sugerem cinco passos para aumentar a tributação dos Governos: o primeiro é taxar mais as grandes empresas e oligopólios em setores de alta taxa de retorno. O segundo passo seria uma reforma tributária global, taxando pessoas jurídicas, no mundo, em no mínimo $25 \%$. A intenção é evitar que a arrecadação migre para países com tributação menor. Outro ponto seria introduzir impostos progressivos para os serviços digitais. O quarto passo é uma medida de transparência com relatórios de todos os países e empresas que se beneficiarem da ajuda pública e, finalmente, publicar, também os recursos em contas offshore.

A pandemia pode lançar mais meio bilhão de pessoas à pobreza no Mundo, mas cabe aos governantes de todas as nações se mobilizarem, de forma mais rápida, para tentativas de reerguimento de suas economias e no Brasil não será diferente. Se está falando de uma Reforma Tributária ampla e efetiva, que ataque a tributação sobre o consumo, mas abarque também a tributação sobre a renda e o patrimônio, visando um maior equilíbrio e favorecendo uma melhor distribuição de renda.

Passada a pandemia, a retomada da economia demandará criatividade e agilidade do Governo, e a política tributária terá um papel decisivo para resolver as necessidades imediatas 
(incluindo salvar empregos e, indiretamente, vidas) e direcionar efeitos de longo prazo.

Nesse cenário, o planejamento tributário, nos termos e limites da lei, se tornará uma prática cada vez mais necessária. Espera-se, no menor prazo possível, ver um sistema tributário nacional moderno e equilibrado, que auxilie o país no caminho do crescimento sustentável.

\section{Conclusão}

É a primeira vez que o país vivencia uma crise de saúde nessa escala e com consequências tão graves na economia. A lição que fica é que agora, mais do que nunca, não podem ser paralisados os trabalhos da Reforma Tributária, mas, pelo contrário, deve ser priorizado o seu andamento com a produção de um texto único pela Comissão Mista a ser discutido e votado no Congresso Nacional ainda esse ano.

Dessa forma se pode dizer que nem tudo está perdido, apesar do ambiente inseguro e instável na economia em função da crise provocada pelo Coronavírus, o momento agora é de total reflexão entre os Poderes Legislativo, Executivos e Judiciário para a criação de um ambiente favorável para aprovar uma das propostas de Reforma Tributária ou a unificação das PECs vigentes. Do ponto de vista de crescimento, para que a economia possa retomar e os negócios ganhem uma nova dimensão é prioritário uma Reforma Tributária, que busque um sistema tributário mais fácil de ser compreendido por todos os brasileiros.

O país tem um sistema tributário, que está vigente o princípio da não cumulatividade, ou seja, sendo sistematizado exatamente mediante a aplicação do método de crédito do tributo em análise, através do qual o valor do tributo devido na etapa anterior é registrado como crédito fiscal para ser utilizado na apuração do débito referente à transação corrente. Por exemplo, uma fábrica montadora de veículos, quando essa adquire os insumos para a fabricação dos veículos, essa tem o direito ao crédito dos tributos indiretos (ICMS, IPI, PIS, COFINS) para serem compensados com os débitos os mesmos tributos quando a fábrica produzir o veículo para ser comercializado.

Com isso, o primeiro ponto que deve ser tomado como prioridade em um cenário pós-COVID-19 diz respeito à condução de uma proposta de Reforma Tributária profunda que torne o sistema tributário mais enxuto, ou seja, sem tantas normas editadas diariamente sobre diversos tributos e, com uma carga tributária mais baixa do que a atual para as empresas.

Desse modo, poderá o país atrair mais investimentos, tornando-se mais competitivo dentro do ambiente de negócios global e, consequentemente, acelerando a geração de empregos que, por sua vez, contribuirá para o aquecimento da economia brasileira.

O Brasil não tem tempo a perder mesmo com o excesso de desgastes nos últimos dias com trocas de ministérios e discussões com outros poderes, com gasto desnecessário de energia, principalmente, entre o Executivo e o Legislativo.

Pode-se dizer, por exemplo, que os impostos devem ser destinados a programas de geração de emprego e de inclusão social, tais como: plano de reforma agrária; crédito rural para expansão da agricultura familiar; plano de construção de habitação popular; saneamento e reurbanização de áreas degradadas nas cidades.

Outra parte dos impostos arrecadados, segundo o fisco, tem de ser direcionada à construção e recuperação de estradas; investimentos em infraestrutura; construção de portos e aeroportos; incentivos para a produção agrícola e industrial; segurança pública; estímulo à pesquisa científica; desenvolvimento de ciência e tecnologia; cultura e esporte, e à defesa do meio ambiente.

Outro aspecto importante é que paralelamente ao serviço público, existe também a burocracia. É como se andassem de mãos dadas. Basta parar para pensar que é muito comum, por exemplo, que prefeitos ou secretários de saúde falem que determinado posto atende a um número enorme de pessoas.

Outra relevante questão é o salário. Apesar da estabilidade ser um dos maiores atrativos do serviço público, a maioria dos servidores está descontente com a sua remuneração. Médicos e professores ganham muito mais na iniciativa privada do que nos hospitais públicos. A questão é verdadeira: se o empregador paga mal, o resultado é a má qualidade do serviço.

O desafio para mudar essa triste realidade é, sem dúvida, uma Reforma Tributária, entretanto, o Brasil nunca discutiu esse assunto em profundidade. Mal a discussão começa, é comum surgir uma briga sobre quem ganha e quem perde com os tributos. Tudo porque ocorre uma verdadeira guerra fiscal dos órgãos arrecadadores das três esferas de poder: federal, estadual e municipal. Cada um quer sua fatia sem se preocupar com o bolo.

Embora diversos países do Mundo estejam adotando medidas para postergar a cobrança de impostos durante a pandemia, no Brasil, a situação não parece ser uma opção. Além disso, está em aberto a possibilidade da criação de um novo imposto para custear os gastos com a COVID-19.

As propostas em debate convergem para a sugestão de cortes em abatimentos de despesas e criação de um novo imposto, assim como novas alíquotas para rendas superiores no Imposto de Renda, incluem tributar lucros e dividendos, hoje isentos, e elevar a taxação de patrimônio e riqueza.

Para concluir este artigo, um ponto essencial que deve ser reforçado é o de que, seja qual for o caminho escolhido pelas esferas do poder, tais quais: o Executivo, Legislativo e Judiciário é hora de buscar um esforço organizado para encaminhar projetos, concretizar estratégias e sair do terreno das ideias.

\section{Referências}

AMARO, L. Direito tributário brasileiro. São Paulo: Saraiva, 2019. 
CAMPOS, A. Reforma Tributária: como reerguer a economia em um mundo pós-pandemia? Disponível em: $<$ https://www. jornalcontabil.com.br/reforma-tributaria-como-reerguer-aeconomia-em-um-mundo-pos-pandemia/> Acesso em: 25 jan. 2020 .

CARVALHO, P.B. Curso de direito tributário. São Paulo: Saraiva, 2019.

CORREIA NETO, C.B. et al. Reforma Tributária - PEC 110/2019, do Senado Federal, e PEC 45/2019, da Câmara dos Deputados. Disponível em: < https://www2.camara.leg.br/ atividade-legislativa/estudos-e-notas-tecnicas/publicacoes-daconsultoria-legislativa/fiquePorDentro/temas/sistema-tributarionacional-jun-2019/reforma-tributaria-comparativo-das-pecs-emtramitacao-2019> Acesso em: 25 jun, 2020.

CUCOLO, E. Retomada pós-coronavírus deve incluir reforma tributária sobre renda e folha de pagamento. Disponível em: $<$ https://www1.folha.uol.com.br/mercado/2020/06/retomadapos-coronavirus-deve-incluir-reforma-tributaria-sobre-renda-efolha-de-pagamento.shtml> Acesso em: 25 jun. 2020.
FALLEIROS, G.T. Transporte debate a reforma tributária. Um Rosto para a Reforma, v.25, n.285, p.19-27, 2019.

MACHADO, C.H.; BALTHAZAR, U.C. A Reforma Tributária como instrumento de efetivação da Justiça Distributiva: uma abordagem histórica. Sequência, n.77, p.221-252, 2017.

ORAIR, R.; GOBETTI, S. Reforma Tributária no Brasil: princípios norteadores e propostas em debate. Novos Estud. CEBRAP, v. 37, n. 2, p.213-244, 2018.

PEROBA, L.R.; CORREA, A. As lições da crise da covid-19 e a reforma tributária. 2020. Disponivel em: <https://www. migalhas.com.br/depeso/326862/as-licoes-da-crise-da-covid19-e-a-reforma-tributaria> Acesso em: 25 jun. 2020.

SABBAG, Eduardo. Manual de direito tributário. 12a ed. São Paulo: Saraiva, 2020

ZUGMAN, D.L. Reflexões sobre as possíveis razões para não ocorrer uma reforma tributária no Brasil. Rev. Direito GV, v. 12, n.3, p.610-631, 2016. 